\title{
Improving chickpea yield by incorporating resistance to ascochyta blight
}

\begin{abstract}
Ascochyta blight [Ascochyta rabiei (Pass.) Lab.] is the most destructive disease of chickpea (Cicer arietinum $\mathrm{L}$.), but it can be managed effectively by the use of resistant cultivars. Therefore, a breeding programme was initiated during 1977-78 at ICARDA, Syria, to breed blight-resistant, high-yielding chickpeas with other desirable agronomic traits. Crosses were made in main season at Tel Hadya, Syria, and the $\mathrm{F}_{1} \mathrm{~s}$ were grown in the off season at Terbol, Lebanon. The $\mathrm{F}_{2}, \mathrm{~F}_{4}$ and $\mathrm{F}_{5}$ generations were grown in a blight nursery in the main season where blight epidemic was artificially created. The plants and progenies were scored for blight resistance and other traits. The $\mathrm{F}_{3}$ and $F_{6}$ generations were grown in the off season under normal day length to eliminate late-maturing plants. The pedigree method of breeding was followed initially, but was later replaced by the $\mathrm{F}_{4}$-derived family method. The yield assessment began with $\mathrm{F}_{7}$ lines, first at ICARDA sites and later internationally. A total of 1584 ascochyta blight-resistant chickpea lines were developed with a range of maturity, plant height, and seed size not previously available to growers in the blight-endemic areas in the Mediterranean region. These included 92 lines resistant to six races of the ascochyta pathogen, and 15 large-seeded and 28 early maturity lines. New cultivars produced $33 \%$ more seed yield than the original resistant sources. The yield of chickpea declined by $340 \mathrm{~kg} \mathrm{ha}^{-1}$, with an increase in blight severity by one class on a 1-9 scale, reaching zero yield with the 8 and 9 classes. Development of blight-resistant lines made the introduction of winter sowing possible in
\end{abstract}

Joint contribution from ICARDA and ICRISAT. ICRISAT Journal Article no. JA 1886.

Communicated by J. MacKey

K. B. Singh ( $(\mathbb{})$

ICRISAT-ICARDA Kabuli Chickpea Project,

International Center for Agricultural Research

in the Dry Areas (ICARDA), P.O. Box 5466, Aleppo, Syria

M. V. Reddy

Crop Protection Division,

International Crops Research Institute for the Semi-Arid

Tropics (ICRISAT), Patancheru, A.P. 502 324, India the Mediterranean region with the prospect of doubling chickpea production. Twenty three cultivars have been released so far in 11 countries.

Key words Chickpea. Cicer arietinum . Disease resistance $\cdot$ Ascochyta blight $\cdot$ Breeding

\section{Introduction}

Chickpea (Cicer arietinum L.) is the third most important pulse crop in the world, but it ranks first in the Indian subcontinent and the Mediterranean basin (F.A.O. Production Yearbook 1994). Its average yield of $700 \mathrm{~kg} \mathrm{ha}^{-1}$ is below potential. One reason for the low yield is the susceptibility of the presently grown cultivars to ascochyta blight [Ascochyta rabiei (Pass.) Lab.]. Ascochyta blight is the most destructive disease of chickpea, especially in north-west India, Pakistan, West Asia, North Africa, southern and eastern Europe, and the U.S.A.; these areas contribute twothirds of the world chickpea production (Nene and Reddy 1987). Nene and Reddy (1987) compiled information from seven countries on yield losses to chickpea caused by this disease; they ranged from 10 to $100 \%$ under natural epidemics. In Syria, which has a typical Mediterranean climate, Reddy and Singh (1990a) have reported yield losses of up to $100 \%$ in susceptible cultivars and up to $10 \%$ in resistant cultivars under artificial epidemics.

Because of severe damage caused by blight to chickpea, farmers in the Mediterranean Basin sow the crop during the spring at the end of winter rains, and, indirectly, this causes severe loss in yield. The winter sowing produces 50 to $100 \%$ more seed yield than spring sowing, provided the crop is protected from blight (Singh and Hawtin 1979; Singh 1990). It is, therefore, important to control blight to increase chickpea productivity in both the spring and winter seasons. Cultivation of resistant cultivars is the most practical method of blight management; chemical control is neither economical nor feasible due to the prevalence of prolonged weather conditions favourable to the 
disease. Chickpea lines with resistance at the vegetative stage, and given fungicide protection at the reproductive stage, could ward off blight to a great extent (Reddy and Singh 1990b). But this method is also not recommended at the present low yield level.

Singh (1987) reviewed the work on chickpea breeding for blight resistance. Most of the earlier-bred resistant cultivars could never withstand the epidemics, mainly due to a low level of resistance (Singh and Reddy 1991). Hence such cultivars were not adopted by farmers on a large scale. Recently, however, evaluation of the world collection of chickpea germ plasm has resulted in the identification of lines with high and broad-based resistance to blight (Singh et al. 1981; Reddy and Singh 1984; Singh and Reddy 1993). Many lines also have resistance to multiple races and at multilocations (Singh and Reddy 1990; Reddy et al. 1992; Singh and Reddy 1993). However, these resistance sources were late maturing, with a small pea-shaped seed, and were thus not acceptable in major chickpea-growing countries.

As we have seen, farmers in the Mediterranean region sow their crop in the spring to escape damage from ascochyta blight; and in the Indian subcontinent chickpea is actually being replaced with other remunerative crops, such as wheat. Consequently, yield in the Mediterranean Basin has remained static for several decades while in north-west India and Pakistan production has been reduced by half. To reverse this situation, it was decided to breed cultivars with resistance to ascochyta blight. A breeding programme was thus initiated jointly by ICRISAT and ICARDA at Tel Hadya, Syria, in 1977-78 to develop chickpea cultivars with resistance to ascochyta blight and with a high seed yield. This paper presents the results of this programme.

\section{Materials and methods}

The ascochyta blight-resistant parents for crossing were selected on the basis of their performance in the blight nursery at ICARDA and in multilocation evaluations in the blight-endemic countries. These were ILC 72, ILC 182, ILC 187, ILC 194, ILC 200, ILC 2380, ILC 2506, ILC 2548, ILC 3279, ILC 3856, ILC 4421, ILC 4424, ILC 5586, ILC 5894, ILC 5902, ILC 5909, ILC 5913, ILC 5922, and ILC 5926. Most of these lines were resistant to blight in multiple-location evaluations, but none was resistant at all sites (Reddy et al. 1992) and to all races of A. rabiei (Singh and Reddy 1990, 1993). These lines were late in maturity and had a small seed size. Initially, germ plasm lines were used as resistant parents, but recently breeding lines with resistance and other desirable agronomic attributes have been used as well. Additional information on resistant lines is available with the authors and can be obtained on request. The complementary parents were selected mainly for earliness, large kabuli-type seed, and high yield (Singh and Reddy 1991). Most crosses were made in the main season which extends from November to June at Tel Hadya, Syria. Between 1978 and 1991, 5895 crosses were made (see Table 1). The $\mathrm{F}_{1} \mathrm{~s}$ were advanced in the off season at Terbol under extended day light to facilitate the maturation of late types. The $F_{2}$, $\mathrm{F}_{4}, \mathrm{~F}_{5}$, and $\mathrm{F}_{6}$ generations were evaluated in the ascochyta-blight nursery sown in the winter at Tel Hadya (Reddy and Singh 1984). The $F_{3}$ and $F_{6} / F_{7}$ generations were again advanced in the off season under normal day length at Terbol, Lebanon, to eliminate the latematuring types.

The segregating materials were inoculated with chickpea blight diseased-debris alone from 1978 to 1983 . From 1984 to 1988 they were inoculated with the diseased-debris and a spore suspension of a mixture of four races of $A$. rabiei. From 1989 onwards, diseaseddebris and a spore suspension of a mixture of six races was used (Reddy and Singh 1984; Reddy and Kabbabeh 1985). The humidity in the screening nursery was raised to more than $60 \%$ by sprinkleror mist-irrigation. The segregating materials were interplanted systematically with susceptible cultivars (ILC 1929 or ILC 263) after every $2-10$ rows and around the experimental plot. The repeated susceptible checks at Tel Hadya were killed by blight in all 14 years except in 1984-85 and 1987-88, indicating the effective selection for blight resistance in segregating material.

One high-yielding and moderately resistant cultivar (ILC 482) and one resistant cultivar (ILC 3279) were also planted along with the breeding materials after every 20 rows in an augmented design. Final observations on blight severity were recorded on a 1-9 scale at maturity (Singh et al. 1981).

No selection was made in $\mathrm{F}_{1}$ generation. In $\mathrm{F}_{2} \mathrm{~s}$, the selection was made mainly for blight resistance. $F_{3} s$ grown in the off season were screened to eliminate late-maturing plants. Selections in $F_{4} s$ were made mainly for blight resistance, tall plant height, early-maturity, large seed size, and high seed yield potential. In the $F_{2}$ and $F_{4}$ generations, plants susceptible to cold were rejected at Tel Hadya, because cold tolerance is an important attribute for adaptation in the Mediterranean region. In the $\mathrm{F}_{5}$ to $\mathrm{F}_{7}$ generations, selections were made for blight resistance and other agronomic traits, and the superior, blight-resistant, and high- yielding homozygous progenies were bulked. The bulked seeds were increased in the off season, and yield trials were conducted from the $\mathrm{F}_{7}$ generation onwards. Usually, 30 seeds per cross was grown in $F_{1}$. The population size of the $F_{2}-F_{4}$ bulks was about 2000 plants. In the $F_{5}-F_{6}$ generations the progenies were sown in single $4-m$ rows ( 40 seeds). Details of the materials grown in each season are given in Table 1.

The pedigree method was used in the early years (1978-1985). In later years (1985-1992), the bulk-pedigree method was followed, in which the materials were grown in bulks until the $F_{4}$ generation. Single-plant selections were made in the $\mathrm{F}_{4}$, and $\mathrm{F}_{4}$-derived $\mathrm{F}_{5}$ progenies were grown. The promising and homozygous $F_{5} / F_{6}$ progenies were bulked and 500 seeds of each bulked line were grown in the off season for seed increase and further purification. The $F_{7} / F_{8}$-derived lines were evaluated in preliminary yield trials in both winter and spring seasons at two locations in Syria (Tel Hadya and Jindiress) and at one location in Lebanon (Terbol), mainly for seed yield, plant height, seed size, maturity, protein content, and blight resistance in both field and greenhouse, against the mixture of six races. The lines selected in the $F_{7}$ yield trials and resistant to blight were made available to national programmes for evaluation under local conditions through the ICARDA International Legume Testing Program.

During the 1990-91 season, 1344 blight-resistant breeding lines developed between 1980 and 1989 were re-evaluated for resistance to ascochyta blight by inoculating them with diseased debris and a spore suspension of a mixture of six races. Only 117 lines were resistant to six races. During the 1991-92 season, the above 117 lines and 240 lines which were developed during 1990 and 1991, together with 19 blight-resistant germ plasm lines and four high-yielding land races, were evaluated for yield under blight and blight-free conditions. An alpha design with two replications was adopted. Because of the large number of entries, the plot size was two rows of $2.5 \mathrm{~m}$ length spaced at $45 \mathrm{~cm}$ apart. The experiment was conducted in two adjoining fields. One set was protected from ascochyta blight by repeated sprays of the fungicide chlorothalonil (tetrachloroisophthalonitrite) at the rate of $0.8 \mathrm{~kg}$ a.i. $\mathrm{ha}^{-1}$. Another set was inoculated with diseased debris and a spore suspension mixture of the six races. Observations were recorded on: days to $50 \%$ flowering and maturity, plant height, biological yield, seed yield, and 100-seed weight under both conditions. In diseased plots, data were also collected on ascochyta blight severity on a 1-9 scale, where $1=$ free from disease damage and $9=$ all plants killed (Singh et al. 1981). Due to poor stands, data were not collected on three of the lines.

Data were analyzed following the alpha design developed by Paterson and Williams (1976). The analysis of variance for other experiments was done following Gomez and Gomez (1984). 


\section{Results}

Over the 14-year period (1977-78 to 1990-91), 5895 crosses involving ascochyta blight-resistant germ plasm lines and lines with early maturity, large kabuli-type seed, and high yield, were made (Table 1). Out of about 400 crosses made each year, $25 \%$ of the crosses involved one backcross with a high-yielding parent. From the material that resulted from these crosses, 1584 ascochyta blight-resistant breeding lines were developed and furnished to ascochyta-blight endemic countries for further selection under local conditions and for possible release as cultivars.

Performance of blight-resistant lines under diseased and disease-free conditions

Three hundred and fifty seven resistant breeding lines, 19 resistant germ plasm lines, and four high-yielding blightsusceptible land races were evaluated under diseased and disease-free conditions during 1991-92. No disease was noted in the fungicide-protected plots, whereas the disease developed in epidemic form in the inoculated plots; the susceptible check lines planted after every nine test entries were killed. The mean seed yields under diseased conditions were 1813,1363 , and $386 \mathrm{~kg} \mathrm{ha}^{-1}$ for resistant breeding lines, resistant germ plasm lines, and susceptible highyielding landraces, respectively (Table 2), and the differences in yield were statistically significant. Under diseasefree conditions, the corresponding mean seed yields were 2698, 2141 and $2956 \mathrm{~kg} \mathrm{ha}^{-1}$ (Table 3). These results showed that an overall $33 \%$ improvement in yield has been achieved in resistant germ plasm lines through breeding, and that landraces cannot usefully be grown under diseased conditions.

The yield performance of the ten highest yielding breed ing lines, one each of the highest yielding germ plasm line and landrace under diseased and disease-free conditions, is shown in Fig. 1. Improvement in yield through breeding over resistant parental lines and susceptible land races is again shown. Under disease-free conditions, some resistant breeding lines produced over $4000 \mathrm{~kg} \mathrm{ha}^{-1}$ yield, whereas the highest yields of the germ plasm line and landrace were 2865 and $3410 \mathrm{~kg} \mathrm{ha}^{-1}$, respectively. Under diseased conditions, the gain in yield of the resistant breeding line over the highest-yielding landrace was $142 \%$.

Correlations of seed yield under diseased conditions with other characters are shown in Table 4. Seed yield was significantly $(P \leq 0.05)$ correlated with ascochyta-blight re-

Table 1 Breeding materials generated in the hybridization programme for the development of chickpea lines with ascochyta-blight resistance and desirable agronomic characters, 1977 to 1991, ICARDA, Syria (MS=main season, OS=off season)

\begin{tabular}{|c|c|c|c|c|c|c|c|c|c|c|c|}
\hline \multirow[t]{3}{*}{ Year } & & \multicolumn{10}{|c|}{ No. of materials in different segregating generations } \\
\hline & & \multirow[t]{2}{*}{$\mathrm{F}_{0}$} & \multirow[t]{2}{*}{$F_{1}$} & \multirow{2}{*}{$\begin{array}{l}\mathrm{F}_{2} \\
\text { bulk }\end{array}$} & \multicolumn{2}{|l|}{$\mathrm{F}_{3}$} & \multicolumn{2}{|l|}{$\mathrm{F}_{4}$} & \multicolumn{3}{|c|}{ Progenies } \\
\hline & & & & & Bulk & Prog. & Bulk & Prog. & $\mathrm{F}_{5}$ & $\mathrm{~F}_{6}$ & $\mathrm{~F}_{7}$ \\
\hline $1977-78$ & MS & 148 & - & - & - & - & - & - & - & - & - \\
\hline \multirow[t]{2}{*}{$1978-79$} & MS & 221 & 148 & - & - & - & - & - & - & - & - \\
\hline & OS & - & 202 & 148 & - & - & - & - & - & - & - \\
\hline \multirow[t]{2}{*}{$1979-80$} & MS & 276 & 31 & 170 & 148 & - & - & - & - & - & - \\
\hline & OS & - & 265 & 19 & 126 & 1822 & - & - & - & - & - \\
\hline \multirow[t]{2}{*}{$1980-81$} & MS & 302 & 98 & 227 & 35 & 311 & 30 & 1379 & - & - & - \\
\hline & OS & 34 & 325 & 9 & - & 1545 & 16 & 653 & 1765 & - & - \\
\hline \multirow[t]{2}{*}{$1981-82$} & MS & 351 & 45 & 269 & 51 & 351 & - & 1292 & 2641 & 4808 & - \\
\hline & OS & - & 191 & 15 & - & 1007 & - & 1099 & - & - & 119 \\
\hline \multirow[t]{2}{*}{$1982-83$} & MS & 375 & - & 179 & 27 & 2479 & - & 149 & 2500 & 1299 & 941 \\
\hline & OS & - & 305 & - & - & 2008 & - & 1316 & - & - & 111 \\
\hline \multirow[t]{2}{*}{$1983-84$} & MS & 401 & - & 284 & - & 3407 & - & 1825 & 1331 & 1830 & 924 \\
\hline & OS & - & 337 & - & - & 5369 & - & 127 & - & - & 123 \\
\hline \multirow[t]{2}{*}{$1984-85$} & MS & 430 & - & 349 & - & - & 449 & 7299 & 1013 & 463 & 519 \\
\hline & OS & 50 & 422 & $\vec{r}$ & 87 & - & - & 1181 & 34 & - & 314 \\
\hline \multirow[t]{2}{*}{$1985-86$} & MS & 556 & - & 396 & 76 & - & - & 1677 & 6531 & 815 & 687 \\
\hline & OS & 48 & 352 & $\overline{-}$ & - & 5190 & - & - & - & - & 363 \\
\hline \multirow[t]{2}{*}{$1986-87$} & MS & 549 & - & 296 & - & - & - & 8717 & 800 & 2420 & - \\
\hline & OS & 73 & 429 & $-\overline{0}$ & 293 & - & - & - & - & - & 383 \\
\hline \multirow[t]{2}{*}{$1987-88$} & MS & 444 & - & 358 & 292 & - & - & 5878 & 6438 & 1353 & - \\
\hline & OS & 59 & 419 & - & 250 & - & 245 & - & - & - & 343 \\
\hline \multirow[t]{2}{*}{$1988-89$} & MS & 521 & - & 341 & 24 & - & - & 7351 & 7102 & 3182 & - \\
\hline & OS & $\begin{array}{r}38 \\
570\end{array}$ & 377 & - & 239 & - & 24 & - & - & - & 296 \\
\hline \multirow[t]{2}{*}{$1989-90$} & MS & 579 & - & 361 & 367 & 838 & 114 & 7837 & 4084 & 1220 & - \\
\hline & OS & 79 & 320 & 4 & 307 & 150 & - & - & - & - & 319 \\
\hline \multirow[t]{2}{*}{$1990-91$} & MS & 335 & - & 266 & 422 & 79 & 310 & 542 & 10686 & 2146 & - \\
\hline & OS & 26 & 241 & - & 178 & - & 19 & - & - & - & 412 \\
\hline \multicolumn{2}{|l|}{ Total } & 5895 & 4507 & 3691 & 2922 & 24556 & 1207 & 48322 & 44925 & 19536 & 5854 \\
\hline
\end{tabular}


Table 2 Summary of the performance of blight-resistant breeding and germ plasm lines, and blight susceptible high-yielding land races under diseased conditions at ICARDA, Syria 1991-92. AB=ascochyta-blight score, DFLR=days to $50 \%$ flowering, DMAT=days to maturity, PLHT=plant height $(\mathrm{cm}), B Y L D=$ biological yield $(\mathrm{kg} / \mathrm{ha})$, SYLD=seed yield $(\mathrm{kg} / \mathrm{ha}), 100 \mathrm{SW}=100$-seed weight $(\mathrm{g})$

\begin{tabular}{lccrr}
\hline Variable & Mean & Range & SE $( \pm)$ & CV $(\%)$ \\
\hline Resistant & breeding lines & $(357)$ & \\
AB & 3.2 & $2.5-5.5$ & 0.021 & 12.46 \\
DFLR & 139 & $133-147$ & 0.151 & 2.05 \\
DMAT & 192 & $189-196$ & 0.072 & 0.70 \\
PLHT & 49 & $30-70$ & 0.380 & 14.67 \\
BYLD & 4536 & $349-7982$ & 64.240 & 26.76 \\
SYLD & 1812 & $193-3080$ & 25.369 & 26.44 \\
100SW & 33 & $15-47$ & 0.284 & 16.13 \\
Resistant germ & plasm lines $(19)$ & & \\
AB & 3.3 & $3.0-8.0$ & 0.263 & 34.83 \\
DFLR & 140 & $138-146$ & 0.604 & 1.88 \\
DMAT & 191 & $189-194$ & 0.299 & 0.68 \\
PLHT & 47 & $35-58$ & 1.648 & 15.41 \\
BYLD & 3131 & $11-5201$ & 380.312 & 52.94 \\
SYLD & 1363 & $34-2197$ & 159.296 & 50.94 \\
100SW & 24 & $18-30$ & 1.036 & 18.89 \\
Susceptible high-yielding landraces $(4)$ & & \\
AB & 7.4 & $4.0-9.0$ & 1.145 & 31.06 \\
DFLR & 136 & $127-142$ & 3.210 & 4.72 \\
DMAT & 192 & $191-193$ & 0.617 & 0.56 \\
PLHT & 41 & $39-43$ & 1.068 & 4.56 \\
BYLD & 1146 & $0-3229$ & 1057.57 & 159.87 \\
SYLD & 386 & $0-1275$ & 446.271 & 200.18 \\
100SW & 31 & $26-36$ & 2.968 & 16.80 \\
\hline
\end{tabular}

Table 3 Summary of performance of blight-resistant breeding and germ plasm lines and blight-susceptible high-yielding land races under disease-free conditions at ICARDA, Syria 1991-92

\begin{tabular}{|c|c|c|c|c|}
\hline Variable & Mean & Range & $\mathrm{SE}( \pm)$ & CV $(\%)$ \\
\hline \multicolumn{5}{|c|}{ Resistant breeding lines (357) } \\
\hline DFLR & 134 & $129-152$ & 0.116 & 1.62 \\
\hline DMAT & 183 & $180-186$ & 0.065 & 0.67 \\
\hline PLHT & 51 & $35-70$ & 0.363 & 13.39 \\
\hline BYLD & 6126 & $770-9123$ & 51.976 & 15.98 \\
\hline SYLD & 2698 & $414-4059$ & 25.163 & 17.57 \\
\hline $100 \mathrm{SW}$ & 32 & $18-44$ & 0.248 & 14.69 \\
\hline \multicolumn{5}{|c|}{ Resistant germ plasm lines (19) } \\
\hline DFLR & 136 & $132-139$ & 0.474 & 1.48 \\
\hline DMAT & 183 & $181-186$ & 0.328 & 0.76 \\
\hline PLHT & 50 & $37-60$ & 1.459 & 12.45 \\
\hline BYLD & 5013 & $2061-8099$ & 316.059 & 26.75 \\
\hline SYLD & 2141 & $635-2865$ & 130.193 & 25.80 \\
\hline $100 \mathrm{SW}$ & 23 & $18-28$ & 0.783 & 14.20 \\
\hline \multicolumn{5}{|c|}{ Susceptible high-yielding landraces (4) } \\
\hline DFLR & 129 & $117-135$ & 4.002 & 6.20 \\
\hline DMAT & 182 & $181-184$ & 0.537 & 0.59 \\
\hline PLHT & 39 & $36-41$ & 1.141 & 5.88 \\
\hline BYLD & 5995 & $4627-7290$ & 628.951 & 20.98 \\
\hline SYLD & 2956 & $2377-3410$ & 222.313 & 15.04 \\
\hline $100 \mathrm{SW}$ & 40 & $28-58$ & 6.291 & 31.43 \\
\hline
\end{tabular}
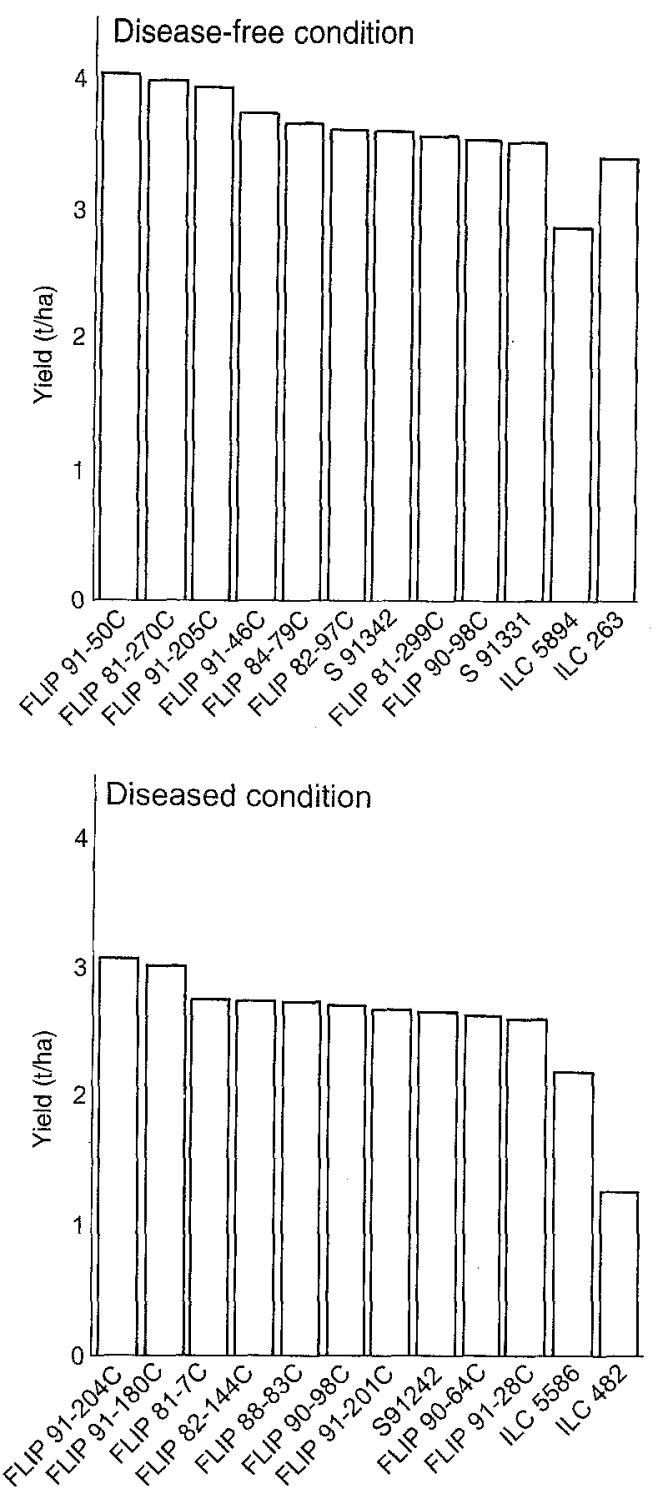

Fig. 1 Yield performance of the ten highest-yielding chickpea ascochyta blight-resistant breeding lines compared with the best resistant germ plasm line (ILC 5894, ILC 5586) and landraces (ILC 263, ILC 482) under diseased and disease-free conditions in a replicated yield trial, Tel Hadya, Syria, 1991-92

sistance; the higher the resistance, the better the yield. Seed yield had the highest correlation of $r=0.829$ ( $P \leq 0.01)$ with biological yield. Whereas ascochyta-blight resistance was significantly correlated with late maturity and plant height in resistant germ plasm lines, it had no association with maturity and plant height in resistant breeding lines. This is an important achievement of breeding because seed yield in chickpea is strongly correlated with earliness.

The mean seed yields $\left(\mathrm{kg} \mathrm{ha}^{-1}\right)$ of lines in different ascochyta-blight susceptibility classes on the 1-9 scale were: for class $2=1895$ (one entry), $3=1847 \pm 27$ (316 entries), $4=1564 \pm 64.2$ (52 entries), $5=1158 \pm 100$ (five entries), $6=779 \pm 136.7$ (two entries), $8=0$ (three entries), and $9=0$ (one entry). There were no entries in classes 1 and 7 . The seed yield was the highest in class 2 ; and there was a con- 
Table 4 Correlation of seed yield of chickpea ascochyta-blight lines with other characters under diseased conditions at ICARDA, Syria 1991-92

\begin{tabular}{|c|c|c|c|c|c|c|}
\hline $\begin{array}{l}\text { Char- } \\
\text { acters }\end{array}$ & DFLR & DMAT & PLHT & BYLD & SYLD & $100 \mathrm{SW}$ \\
\hline ABR & $-0.377 * *$ & $0.147 * *$ & $-0.163 * *$ & $-0.393^{* *}$ & $-0.428 * *$ & -0.080 \\
\hline DFLR & & $0.410 * *$ & $0.238^{* * *}$ & -0.060 & $-0.231 * *$ & $0.154 * *$ \\
\hline DMAT & & & $0.241 * *$ & $0.138 * *$ & $-0.130 * *$ & $0.435 * *$ \\
\hline PLHT & & & & $0.592 * *$ & $0.306 * *$ & $0.492 * *$ \\
\hline BYLD & & & & & $0.857^{* * *}$ & $=0.499 * *$ \\
\hline SYLD & & & & & & $0.309^{* * *}$ \\
\hline
\end{tabular}

** Significant at $1 \%$ level

tinuous decline in yield as the disease severity increased from 2 to 9 . There was zero yield in the lines with a rating of 8 or 9 . The regression equation for yield $\left(\mathrm{kg} \mathrm{ha}^{-1}\right)$ was: $[(S Y L D=2874.5 \pm 127.0)-(340.7 \pm 38.8)(\mathrm{AB})]$ where $\mathrm{AB}$ is the ascochyta-blight score (1-9). The graphical relationship is presented in Fig. 2. The seed yield of chickpea declined by $340 \mathrm{~kg} \mathrm{ha}^{-1}$ with an increase in blight severity by one class on the 1-9 scale.

\section{Blight-resistant large-seeded kabuli lines}

Out of 357 breeding lines, 92 lines with resistance to six races of blight, both in field and greenhouse, and with typical kabuli seed, were identified. Ten large-seeded lines are shown in Table 5. The seed weight of these lines was $40-75 \%$ heavier than in resistant germ plasm lines. This has been achieved by crossing resistant germ plasm lines with large-seeded high-yielding susceptible lines. Some of these 92 lines, such as FLIP 84-124C, FLIP 90-96C, FLIP 91-19C, FLIP 91-28C and FLIP 91-62C, have a higher level of resistance than the original sources of resistance used in hybridization. These have resulted mainly from transgressive segregation in crosses between resistant or among moderately resistant breeding lines and germ plasm lines. ILC 72 was the most frequent parent in crosses resulting in blight-resistant kabuli lines. This line also showed broad-based resistance to blight in multilocation evaluation (Reddy et al. 1992). It was the resistant parent in 8 out of the 92 blight-resistant lines developed. Another parent that was frequently represented in selected crosses was ILC 3870, a tall and blight-tolerant line. High-yielding, blight-susceptible lines, which frequently appeared in the parentage of newly developed breeding lines were ILC 215 (seven lines), ILC 1920 and ILC 1919 (six lines each). As the breeding materials were exposed to diseased debris and spore suspensions of mixtures of the six races of the pathogen, the resistance in these lines is expected to be broad-based.

\section{Blight-resistant early maturing lines}

A major achievement of the breeding programme was the development of early maturing lines with blight resistance.

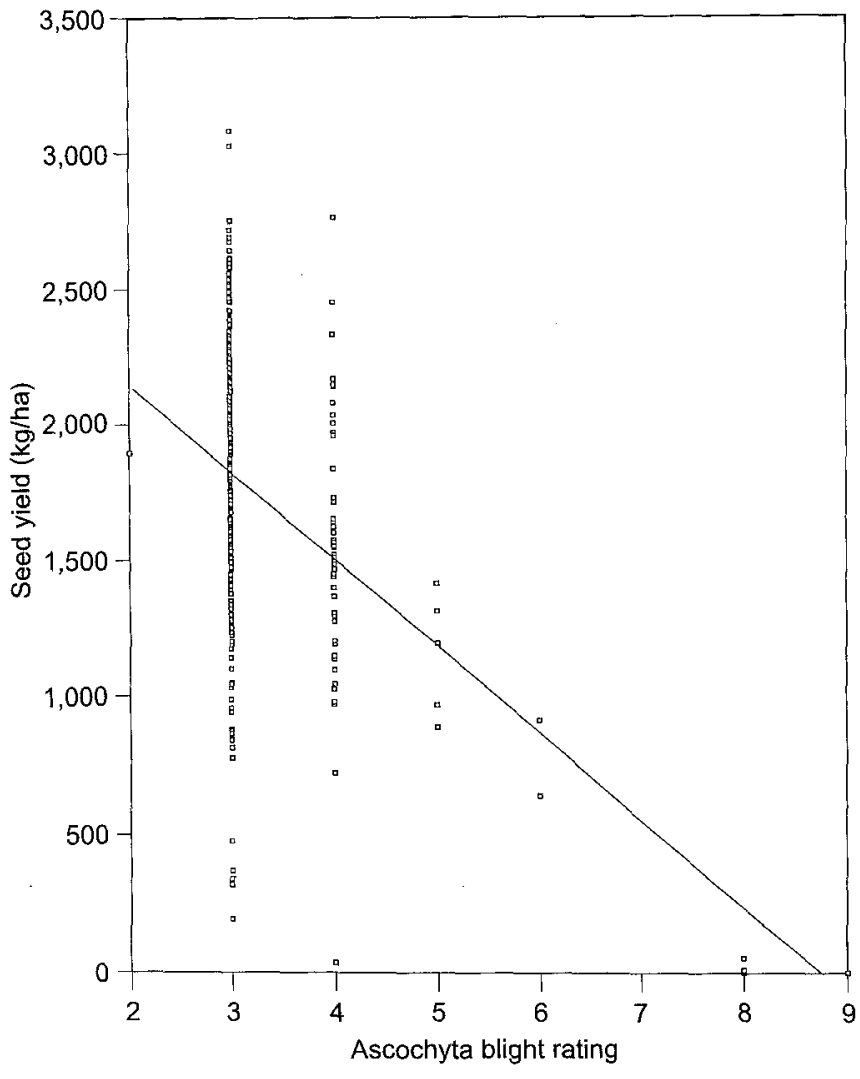

Fig. 2 Relationship between ascochyta-blight disease score and yield in chickpea

The earliest line among the resistant germ plasm lines was ILC 2380, taking 132 days to $50 \%$ flowering under Tel Hadya conditions. The days to $50 \%$ flowering in other resistant lines ranged from 133 to 141 . Through hybridization, 28 lines were developed with blight resistance and earlier flowering than the earliest of the resistant germ plasm lines and ten of them are shown in Table 5. The days to $50 \%$ flowering in these 28 lines ranged from 129 to 131 days. These have the same, or earlier, maturity than the highest-yielding blight-tolerant germ plasm line ILC 482 (132 days) and the locally adapted Syrian local (131 days). The development of early lines was possible due to use of a early maturing parents, such as ILC 1919, and use of the off-season screening facility. The decreasing day-length in the off season (July-Oct) helped in the elimination of photoperiod-sensitive lines. The lines with blight resistance and early maturity will be valuable in chickpea-producing regions at lower latitudes which have short growing seasons, and will be useful for spring sowing in the Mediterranean region.

\section{Discussion}

A large ascochyta-blight resistance breeding programme was initiated at ICARDA, Syria, during 1977-78. Twenty 
Table 5 Newly-bred chickpea lines with their reaction to six races of $A$. rabiei under both field and greenhouse conditions, $100-\mathrm{SW}$ and days to $50 \%$ flower, ICARDA, Syria

\begin{tabular}{lll}
\hline FLIP no. Pedigree & $\begin{array}{l}\text { Blight score } \\
\frac{\text { Field Green- }}{\text { house }}\end{array}$ & $\begin{array}{l}\text { 100-SW } \\
\text { weight }\end{array}$ \\
\hline
\end{tabular}

\begin{tabular}{|c|c|c|c|c|c|}
\hline \multicolumn{6}{|c|}{ Ten large seeded blight-resistant lines } \\
\hline $84-86 \mathrm{C}$ & ILC $72 \times$ ILC 215 & 3 & 3.5 & 36.3 & 133 \\
\hline $90-3 \mathrm{C}$ & $($ FLIP 81-65C $\times$ ILC 187) $\times$ FLIP 84-19C & 4 & 4 & 38.7 & 135 \\
\hline $90-104 \mathrm{C}$ & S $85088 \times$ ILC 3870 & 3 & 3.5 & 36.7 & 136 \\
\hline $91-18 \mathrm{C}$ & ILC $1919 \times$ FLIP 84-99C & 3 & 3 & 37.1 & 132 \\
\hline $91-20 \mathrm{C}$ & $($ ILC $136 \times$ FLIP 84-18C) $\times$ FLIP 84-78C & 4 & 4 & 43.7 & 137 \\
\hline $91-24 \mathrm{C}$ & FLIP 84-17C × ILC 4921 & 4 & 4 & 39.4 & 136 \\
\hline $91-38 \mathrm{C}$ & S $85088 \times$ ILC 3870 & 3 & 3.5 & 38.7 & 135 \\
\hline $91-50 \mathrm{C}$ & FLIP $85-42 C \times$ FLIP $86-93 \mathrm{C}$ & 3 & 4 & 39.3 & 134 \\
\hline $91-52 \mathrm{C}$ & $($ FLIP $85-2 C \times$ FLIP 84-93C) $\times$ FLIP 85-2C & 4 & 4 & 43.7 & 135 \\
\hline $91-58 \mathrm{C}$ & ILC $1254 \times$ FLIP 84-182C & 3 & 4 & 36.3 & 133 \\
\hline \multicolumn{6}{|c|}{ Ten early maturity blight-resistant lines } \\
\hline $81-299 \mathrm{C}$ & ILC $618 \times$ ILC 183 & 4 & 4.5 & 23.6 & 130 \\
\hline $88-83 \mathrm{C}$ & FLIP $81-100 \mathrm{C} \times$ ILC 200 & 4 & 3.5 & 22.6 & 132 \\
\hline $90-98 \mathrm{C}$ & FLIP $83-7 \mathrm{C} \times$ FLIP $84-92 \mathrm{C}$ & 4 & 3.5 & 33.3 & 131 \\
\hline $91-18 \mathrm{C}$ & ILC 1919 × FLIP 84-99C & 3 & 3 & 37.1 & 132 \\
\hline $91-22 \mathrm{C}$ & ILC $1919 \times$ FLIP 84-99C & 4 & 3.5 & 33.0 & 131 \\
\hline $91-41 \mathrm{C}$ & ICC $14212 \times$ FLIP $83-98 C$ & 3 & 4 & 31.9 & 131 \\
\hline $91-45 \mathrm{C}$ & FLIP 81-293C $\times$ FLIP 84-93C & 4 & 4 & 31.1 & 131 \\
\hline $91-46 \mathrm{C}$ & FLIP 81-293C $\times$ FLIP 84-93C & 3 & 4 & 31.6 & 132 \\
\hline $91-207 C$ & FLIP 84-124C $\times$ FLIP 84-93C & 3 & 4.5 & 32.5 & 131 \\
\hline S 91405 & FLIP 84-124C $\times$ FLIP 84-93C & 4 & 4 & 32.4 & 131 \\
\hline \multirow{2}{*}{\multicolumn{2}{|c|}{$\begin{array}{l}\text { ILC } 263 \text { (Susceptible check) } \\
\text { ILC } 3279 \text { (Resistant check) }\end{array}$}} & 9 & 9 & 36.4 & 131 \\
\hline & & 4 & 4 & 28.0 & 139 \\
\hline \multicolumn{2}{|l|}{ Mean } & 3.2 & 4.5 & 32.0 & 134 \\
\hline \multicolumn{2}{|l|}{ CV $(\%)$} & 12.46 & 7.81 & 14.69 & 1.62 \\
\hline \multicolumn{2}{|l|}{$\mathrm{SE} \pm$} & 0.02 & 0.25 & 0.25 & 0.12 \\
\hline
\end{tabular}

thousand germ plasm lines were screened and 14 durable sources of resistance identified (Singh and Reddy 1993). These resistance sources were crossed with lines having large, beige-coloured seeds with early maturity and high yields. In 14 years, 1584 lines were bred with blight resistance, kabuli-type seed, early maturity, large seed, and high yields. For the first time, such materials were made available to researchers in the Mediterranean basin and in the Indian subcontinent. As a result, 11 countries have released 23 cultivars between them. These are: Algeria (FLIP 8479C, FLIP 84-92C), China (FLIP 81-40C, FLIP 81-71C), France (FLIP 81-293C, FLIP 84-188C), Lebanon (FLIP 85-5C), Morocco (FLIP 83-48C, FLIP 84-92C), Pakistan (FLIP 81-293C), Portugal (FLIP 85-17C), Syria (FLIP 82150C), Tunisia (FLIP 83-46C, FLIP 84-79C, FLIP 8492C), Turkey (FLIP 82-259C, FLIP 84-15C, FLIP 85-17C, FLIP 85-14C, FLIP 85-60C, Akcin) and the U.S.A. (Dwelley, Sanford). Another 42 lines are at late stages of evaluation in 14 countries and have the potential for release as cultivars (ICARDA 1994).

With the identification of six physiological races of $A$. rabiei in Syria and 13 races in the West Asia-North Africa region, efforts were made to develop cultivars with durable resistance. We have observed that if a line is resistant to multiple races, it is also resistant at multilocations and may exhibit durable resistance. We have bred 92 lines with resistance to six races. It is expected that such lines, when grown on a large scale, will substantially increase the seed yield, and consequently chickpea production, in the region.

Four major components have led to the successful breeding of ascochyta blight-resistant chickpea lines at ICARDA. First, the development of an easy and reliable large-scale field screening technique has allowed the breeding of cultivars on a planned basis rather than on opportunistic breeding in years of blight epidemics. This technique has also been adopted throughout blight-endemic areas, facilitating a multilocation evaluation of lines. Second, the availability of sources of resistance to multiple races has permitted the development of cultivars with longer life spans. Third, the identification of physiological races has enabled testing of breeding materials against the prevalent races of the pathogen. Fourth, blight-resistant high-yielding cultivars have encouraged European and north American breeders to introduce chickpea cultivation in non-conventional areas. This venture is expected to further increase world chickpea production.

The development of chickpea cultivars with blight resistance has made it possible to sow the crop during winter in the Mediterranean basin with the potential for a doubling of chickpea production (Singh 1990). It is estimated that 125000 ha were sown with blight-resistant cultivars during the 1993-94 winter season in the Mediterranean environments. Farmers have harvested up to $4 \mathrm{tha}^{-1}$ yields on large plots and have used fertilizer and herbicide (Sax- 
ena 1990). Usually, chickpea growers are reluctant to apply such inputs due to low and uncertain yields.

When the ascochyta blight-resistant breeding programme was initiated in 1977-78, selection for resistance was made from the germ plasm collections maintained in the gene bank. These resistant lines were also evaluated for yield performance by national programmes. ILC 482 was resistant to ascochyta blight with a high yield and was therefore released in seven countries as cultivars (Singh et al. 1992). But ILC 482 appeared susceptible in Morocco and Syria in years favourable to disease development. It has now been replaced by cultivars possessing multiplerace resistance. It is expected that FLIP 83-48C and FLIP 84-92C in Morocco and FLIP 82-150C in Syria will have a more durable resistance than ILC 482 . We have initiated a project to pyramid genes for resistance for use in the breeding programme in the hope that cultivars with more durable resistance will be developed in the future. In this, we are using molecular-assisted selection for ascochytablight resistance.

\section{References}

Food and Agriculture Organization of the United Nations Organization (1994) Production yearbook. FAO, Rome, Italy

ICARDA (1994) Legume program annual report for 1993. ICARDA, Aleppo, Syria

Gomez KA, Gomez AA (1984) Statistical procedures for agricultural research, 2nd edn. John Wiley and Sons, New York

Nene YL, Reddy MV (1987) Chickpea diseases and their control. In: Saxena MC, Singh KB (eds) The chickpea. C.A.B. International, Oxon, UK, pp 233-270

Paterson HD, Williams ER (1976) A new class of resolvable incomplete block designs. Biometrika 63:83-92
Reddy MV, Kabbabeh S (1985) Pathogenic variability in Ascochyta rabiei (Pass.) Lab, in Syria and Lebanon. Phytopathol Mediterranea $24: 265-266$

Reddy MV, Singh KB (1984) Evaluation of a world collection of chickpea germ plasm lines for resistance to ascochyta blight. Plant Dis 68:900-901

Reddy MV, Singh KB (1990a) Relationship between ascochyta blight severity and yield loss in chickpea and identification of resistant lines. Phytopathol Mediterranea 29:32-38

Reddy MV, Singh KB (1990b) Management of ascochyta blight of chickpea through integration of host plant tolerance and foliar spraying of chlorothalonil. Indian J Plant Prot 18:65-69

Reddy MV, Singh KB, Malhotra RS (1992) Multilocation evaluation of chickpea germ plasm and breeding lines for resistance to ascochyta blight. Phytopathol Mediterranea 31:59-66

Saxena MC (1990) Problems and potentials of chickpea production in the nineties. In: van Rheenen HA, Saxena MC (eds) Proc 2nd Int Wkhp 'Chickpea in the Nineties'. 4-8 Dec 1989, ICRISAT Center, Patancheru, A.P. 502 324, India

Singh KB (1987) Chickpea breeding. In: Saxena MC, Singh KB (eds) The chickpea. C.A.B. International, Oxon, UK pp 127-162

Singh KB (1990) Winter chickpea: problems and potential in the Mediterranean region. In: Saxena MC, Cubero JI, Wery J (eds) Present status and future prospects of chickpea crop production and improvement in the mediterranean countries. Options mediterraneennes, Serie A: Seminaires Mediterraneens, Numero 9, CIHEAM, Zaragoza, Spain, pp 25-34

Singh KB, Hawtin GC (1979) Winter planting of chickpea. Int Chickpea Newsl No 1:4

Singh KB, Reddy MV (1990) Patterns of resistance and susceptibility to races of Ascochyta rabiei among germ plasms and breeding lines of chickpea. Plant Dis 74:127-129

Singh KB, Reddy MV (1991) Advances in disease resistance breeding in chickpea. Adv Agron 45:191-222

Singh KB, Reddy MV (1993) Resistance to six races of Ascochyta rabiei in the world germ plasm collection of chickpea. Crop Sci 33:186-189

Singh KB, Hawtin GC, Nene YL, Reddy MV (1981) Resistance in chickpeas to Ascochyta rabiei. Plant Dis 65:586-587

Singh KB, Malhotra RS, Saxena MC (1992) Registration of ILC 482 chickpea. Crop Sci 32:826 